\title{
SPATIAL CONTROL OF BONE FORMATION USING A POROUS POLYMER SCAFFOLD CO-DELIVERING ANABOLIC RHBMP-2 AND ANTI-RESORPTIVE AGENTS
}

\author{
Nicole Y.C. Yu ${ }^{1,2, *}$, Marie Gdalevitch ${ }^{1,3}$, Ciara M. Murphy ${ }^{1,2}$, Kathy Mikulec ${ }^{1}$, Lauren Peacock ${ }^{1}$, Jane Fitzpatrick ${ }^{4}$, \\ Laurence C. Cantrill2, ${ }^{2}$, Andrew J. Ruys ${ }^{5}$, Justin J. Cooper-White ${ }^{4}$, David G. Little ${ }^{1,2}$ and Aaron Schindeler ${ }^{1,2}$
${ }^{1}$ Department of Orthopaedic Research \& Biotechnology, Kids Research Institute at Westmead Children's Hospital, Westmead, Australia
${ }^{2}$ Discipline of Paediatrics and Child Health, Faculty of Medicine, University of Sydney, Sydney, Australia
${ }^{3}$ Shriners Hospital for Children, Montreal, Canada

${ }^{4}$ Tissue Engineering and Microfluidics Laboratory, Australian Institute for Nanotechnology and Bioengineering and the School of Chemical Engineering, University of Queensland, Brisbane, Australia

${ }^{5}$ Microscopy Services, Kids Research Institute at Westmead Children's Hospital, Westmead, Australia

${ }^{6}$ School of Aerospace, Mechanical and Mechatronic Engineering, University of Sydney, Sydney, Australia

\begin{abstract}
Current clinical delivery of recombinant human bone morphogenetic proteins (rhBMPs) utilises freeze-dried collagen. Despite effective new bone generation, rhBMP via collagen can be limited by significant complications due to inflammation and uncontrolled bone formation. This study aimed to produce an alternative rhBMP local delivery system to permit more controllable and superior rhBMP-induced bone formation. Cylindrical porous poly(lactic-co-glycolic acid) (PLGA) scaffolds were manufactured by thermally-induced phase separation. Scaffolds were encapsulated with anabolic rhBMP-2 $(20 \mu \mathrm{g}) \pm$ anti-resorptive agents: zoledronic acid $(5 \mu \mathrm{g} \mathrm{ZA})$, ZA pre-adsorbed onto hydroxyapatite microparticles, $(5 \mu \mathrm{g}$ ZA/2 \% HA) or IkappaB kinase (IKK) inhibitor (10 $\mu \mathrm{g}$ PS-1145). Scaffolds were inserted in a 6-mm criticalsized femoral defect in Wistar rats, and compared against rhBMP-2 via collagen. The regenerate region was examined at 6 weeks by $3 \mathrm{D}$ microCT and descriptive histology. MicroCT and histology revealed rhBMP-induced bone was more restricted in the PLGA scaffolds than collagen scaffolds $(-92.3 \% \mathrm{TV}, p<0.01)$. The regenerate formed by PLGA + rhBMP-2/ZA/HA showed comparable bone volume to rhBMP-2 via collagen, and bone mineral density was $+9.1 \%$ higher $(p<0.01)$. Local adjunct ZA/HA or PS-1145 significantly enhanced PLGA + rhBMP-induced bone formation by $+78.2 \%$ and $+52.0 \%$, respectively $(p \leq 0.01)$. Mechanistically, MG-63 human osteoblast-like cells showed cellular invasion and proliferation within PLGA scaffolds. In conclusion, PLGA scaffolds enabled superior spatial control of rhBMP-induced bone formation over clinically-used collagen. The PLGA scaffold has the potential to avoid uncontrollable bone formation-related safety issues and to customise bone shape by scaffold design. Moreover, local treatment with anti-resorptive agents incorporated within the scaffold further augmented rhBMP-induced bone formation.
\end{abstract}

Keywords: Critical-sized bone defect; zoledronic acid; bisphosphonate; IKK-inhibitor; bone morphogenetic protein; bone tissue engineering; biodegradable polymer scaffold; thermally induced phase separation.
*Address for correspondence:

Dr Nicole Y.C Yu

Orthopaedic Research \& Biotechnology

Research Building

The Children's Hospital at Westmead

Locked Bag 4001

Westmead, NSW 2145, Australia

Telephone Number: +61-2-98451451

FAX Number: +61-2-98453078

Email: nicole.yu@sydney.edu.au or: aaron.schindeler@sydney.edu.au

\section{Introduction}

Recombinant human bone morphogenetic proteins (rhBMPs) are commonly used as primary osteoinductive growth factors in orthopaedics and are being increasingly adopted as alternatives to bone graft. The clinical standard is to use purified collagen scaffolds for local rhBMP-2 delivery. Although, collagen is able to bind and retain BMPs, there is a significant burst release resulting in initial high local concentrations. This could lead to increased osteoclastogenesis (Itoh et al., 2001; Kaneko et al., 2000) and premature or exuberant bone resorption (Pradhan et al., 2006). A recent systematic clinical review highlighted how rhBMP delivery via collagen can be limited by both poorly controlled and ectopic bone formation (Carragee et al., 2011). Collagen scaffolds are also described as having inferior scaffold biomechanics and are limited by the potential low risk of prion-disease (DeLustro et al., 1990). In contrast, synthetic biomaterials have the advantages of relative ease of manufacturing, a lack of an immune response, and no risk of disease transfer (DeLustro et al., 1990; Geesink et al., 1999; Kato et al., 2006; Olsen et al., 2003). Inorganic ceramics are limited by the material's brittleness, stiffness, and poor material strength, which restrict the shape of the scaffold. Furthermore, these materials have poor biodegradation rates and material radiopacity, which can complicate bone-healing assessment (Yu et al., 2010a).

Biodegradable poly $(\alpha$-hydroxy acids) polymers are emerging as a promising alternative biomaterial for local BMP delivery over inorganic ceramics and inorganic non-ceramics. One such example is poly(D,L-lacticco-glycolic acid) (PLGA), which is associated with an 
extensive FDA approval history, superior biocompatibility, the potential for controlled drug release, controlled degradation rate, and mouldable form (Sokolsky-Papkov et al., 2007). To improve poly( $\alpha$-hydroxy acids)-based polymer biocompatibility, hydroxyapatite (HA) particles have been added (Maquet et al., 2004; Maquet et al., 2003), since the acidic degradation products of PLGA can result in a local decrease in $\mathrm{pH}$ and an increase in tissue inflammation around the implant (Yu et al., 2010a).

Thermally-induced phase-separation (TIPS) is a solvent-based polymer scaffold fabrication technique for the production of highly porous scaffolds with interconnected pores, which are scaffold characteristics crucial for cell migration, oxygen and nutrient supply to cells, waste transfer, and tissue in-growth (Hollister, 2005; Mooney et al., 1994). TIPS fabrication allows tailored pores size and distribution by controlling the cooling/ quenching regime (i.e. quenching rates and quenching temperature) (Cao et al., 2004a; Cao et al., 2004b). In a precursor study (Yu et al., 2013), we employed a TIPS quenching protocol for the local delivery of rhBMP-2. The resulting $90 \%$ porous PLGA matrix with highly ordered cellular pore structures and high interconnectivity showed superior bone-forming capacity and degradation over slow degrading poly(DL)-lactide (Yu et al., 2013).

Our bone tissue engineering strategy is consistent with the Diamond Model for fracture healing, which proposes that an optimal bone formation outcome is dependent on the selection of type of scaffold or matrix, growth factors, populations(s) of osteogenic cells, and the amount of mechanical loading (Giannoudis et al., 2007). We previously induced ectopic bone formation in a murine model by implantation of TIPS-fabricated PLGA porous scaffold containing rhBMP-2 (Yu et al., 2013). The local delivery muscle implantation model harnessed the boneforming abilities of endogenous osteoprogenitors that are stimulated to form bone with rhBMP-2. To avoid impaired bone formation due to local resorptive forces stimulated by high local rhBMP concentrations (Itoh et al., 2001; Kaneko et al., 2000), rhBMP was encapsulated in our PLGA scaffolds for slow and sustained local delivery (Yu et al., 2013).

When using rhBMPs to induce bone formation in a critical-sized defect or ectopic bone formation model, the newly formed bone is often protected from mechanical loading (i.e. stress-shielded). This can lead to premature bone resorption (Wolff, 1892). Consequently, our bone tissue engineering strategy aims to modulate both bone formation and bone resorption (Little et al., 2005; Yu et al., 2012). This study employs agents from two classes of anti-resorptives: bisphosphonates and IkappaB kinase (IKK) inhibitors. Bisphosphonates are routinely used for the treatment of osteoporosis and other metabolic bone disorders. Nitrogen-containing bisphosphonates (e.g. pamidronate, alendronate, risedronate, ibandronate, and zoledronic acid) inhibit farnesyl pyrophosphate (FPP) synthase, which leads to cellular dysfunction in osteoclasts (Russell et al., 2007). As reviewed by Yu et al. (2012), numerous pre-clinical studies have demonstrated synergy between rhBMPs and bisphosphonates delivered systemically or locally.
To further augment bone formation in a BMP/ZA co-delivery system, a calcium phosphate-based material, such as hydroxyapatite microparticles (HA) could be considered. HA has demonstrated both osteoconductive and anti-inflammatory potential (Calandrelli et al., 2004; Rezwan et al., 2006). Furthermore, zoledronic acid (ZA) has a known affinity to bind to calcium phosphates (in both natural and synthetic forms) and ZA/HA could be preferentially phagocytosed by osteoclasts (Coathup et al., 2001). Emerging anti-resorptive agent, IKK-inhibitor (PS-1145) has been found to induce apoptosis in osteoclast precursors, as well as inhibit osteoclastogenesis and bone erosion (Idris et al., 2010; Idris et al., 2009; Ruocco et al., 2005) and shown potential in augmenting rhBMP-induced bone tissue engineering (Carr et al., 2011).

This study aims to produce an alternative rhBMP local delivery system to a collagen-based system, which permits superior and more controllable rhBMP-induced bone formation. This study utilised a rat critical defect model that does not heal without anabolic intervention (Little et $a l ., 2005)$. As a secondary aim to test the effects of codelivery of anabolic and anti-resorptive agents, we inserted porous scaffolds containing rhBMP-2/ZA or rhBMP-2/ IKK inhibitor PS-1145. Direct comparisons with current collagen-based technologies were used to demonstrate improved bone formation and bone retention, leading to more robust union.

\section{Materials and Methods}

\section{Reagents}

Recombinant human bone morphogenetic protein-2 (rhBMP-2) from the Infuse ${ }^{\circledR}$ Bone Graft Small Kit was purchased from Medtronic (Memphis, TN, USA). Zoledronic acid (ZA) was purchased from Axxora LLC (San Diego, CA, USA). IKK-inhibitor PS-1145 (>98\% HPLC) was purchased from Sigma Aldrich (Sydney, Australia). Poly(D,L-lactide-co-glycolide) (PLGA) biodegradable polymer (lactide:glycolide ratio of 50:50 and inherent viscosity 0.95-1.20 dL/g, Durect, Lactel ${ }^{\circ}$, Pelham, AL, USA) and solvent 1, 4-dioxane (99\% ACS reagent, Ajax Finechem Pty Ltd, Taran Point, Australia) were used for the fabrication of porous PLGA scaffolds. Collagen from the Infuse ${ }^{\circledR}$ Bone Graft Small Kit was used as supplied. Precalcined hydroxyapatite (HA) microparticles with an average diameter $\approx 1.5 \mu \mathrm{m}$ were used (P149, Plasma Biotal Ltd, Derby, UK). Particles were agglomerates of acicular nanoparticles (diameter $\approx 100 \mathrm{~nm}$ x $250 \mathrm{~nm}$ ) (Ruys et al., 1995). ZA was adsorbed to HA following the protocol previously published by Yu et al. (2013). Briefly, ZA/sterile water solution $(1 \mathrm{mg} / \mathrm{mL})$ was incubated with $\mathrm{HA}\left(37^{\circ} \mathrm{C}\right.$ water bath for $24 \mathrm{~h}$ ), filtered, and the remaining $\mathrm{ZA} / \mathrm{HA}$ vacuum-dried (for $8 \mathrm{~h}$ at $-70 \mathrm{kPa}$ and $45^{\circ} \mathrm{C}$ ).

\section{Drug-loaded polymer scaffold fabrication}

Porous PLGA scaffolds containing $20 \mu \mathrm{g}$ rhBMP $-2 \pm 5 \mu \mathrm{g}$ $\mathrm{ZA} \pm \mathrm{HA}$ were fabricated by thermally induced phase separation (TIPS) methods as described previously (Yu et al., 2013). In brief, a PLGA/dioxane stock solution was diluted with dioxane-containing drug \pm HA solutions 
Table 1. Cell viability experimental design.

\begin{tabular}{|c|c|c|c|c|}
\hline Group ID & Scaffold & Anabolic agent & Anti-catabolic agent & $\boldsymbol{n}$ \\
\hline PLGA & PLGA polymer scaffold & - & - & 6 \\
\hline PLGA + BMP & PLGA polymer scaffold & $4 \mu \mathrm{g}$ BMP-2 & - & 6 \\
\hline PLGA + BMP/ZA & PLGA polymer scaffold & $4 \mu \mathrm{g}$ BMP-2 & $1 \mu \mathrm{g} \mathrm{ZA}$ & 6 \\
\hline PLGA + BMP/ZA/HA & PLGA polymer scaffold & $4 \mu \mathrm{g} \mathrm{BMP-2}$ & $1 \mu \mathrm{g} \mathrm{ZA}$ via HA & 6 \\
\hline PLGA + BMP/PS-1145 & PLGA polymer scaffold & $4 \mu \mathrm{g} \mathrm{BMP-2}$ & $20 \mu \mathrm{g}$ PS-1145 & 6 \\
\hline
\end{tabular}

Table 2. Surgical experimental design.

\begin{tabular}{|c|c|c|c|c|}
\hline Group ID & Scaffold & Anabolic agent & Anti-catabolic agent & $\boldsymbol{n}$ \\
\hline PLGA & PLGA polymer scaffold & - & - & 5 \\
\hline PLGA + BMP & PLGA polymer scaffold & $20 \mu \mathrm{g}$ BMP-2 & - & 20 \\
\hline PLGA + BMP/ZA & PLGA polymer scaffold & $20 \mu \mathrm{g}$ BMP-2 & $5 \mu \mathrm{g}$ ZA & 20 \\
\hline PLGA + BMP/ZA/HA & PLGA polymer scaffold & $20 \mu \mathrm{g}$ BMP-2 & $5 \mu \mathrm{g}$ ZA via HA & 20 \\
\hline PLGA+ BMP/PS-1145 & PLGA polymer scaffold & $20 \mu \mathrm{g}$ BMP-2 & $100 \mu \mathrm{g}$ PS-1145 & 20 \\
\hline COL + BMP & Collagen scaffold & $20 \mu \mathrm{g}$ BMP-2 & - & 20 \\
\hline
\end{tabular}

to give a final concentration of $10 \% \mathrm{w} / \mathrm{v}$. The polymer solution and drug/dioxane suspensions were generated by mixing dioxane with polymer pellets or drugs by weight by vortex and sonication. These solutions were then combined and further mixed by vortex to yield the appropriate polymer and drug concentrations. Composite HA/PLGA scaffolds were loaded with $\mathrm{HA}$ at $2 \% \mathrm{w} / \mathrm{w}$. The final solutions were transferred into glass moulds and quenched at a controlled rate $-0.5^{\circ} \mathrm{C} / \mathrm{min}$ from $25^{\circ} \mathrm{C}$ to $-10{ }^{\circ} \mathrm{C}$. The quenched scaffold rods were removed from glass moulds and placed under high vacuum for solvent removal $\left(8 \mathrm{~h},-7.3 \times 10^{-4} \mathrm{mbar}\right)$. Vacuum-dried scaffold rods were sliced transversely with a stainless steel blade into $1 \mathrm{~mm}$ thick disks or $5 \mathrm{~mm}$ long cylinders. For cell culture experimentation, scaffold dimensions were $3 \mathrm{~mm}$ diameter x $1 \mathrm{~mm}$ height. For surgical insertion, scaffolds dimensions were $3 \mathrm{~mm}$ diameter x $5 \mathrm{~mm}$ height. Scaffold drug doses followed Table 1 and Table 2. The scaffolds were UV sterilised ( $5 \mathrm{~min}$ ) prior to surgical insertion and cell culture.

\section{Drug-loaded collagen scaffold preparation}

Porous collagen scaffolds were cut to size ( $5 \mathrm{~mm}$ x $5 \mathrm{~mm}$ ) under sterile conditions from collagen sheets $(4 \mathrm{~mm}$ thickness) supplied from the Infuse ${ }^{\circledR}$ Bone Graft Small Kit. Each scaffold was loaded with $20 \mu \mathrm{g}$ rhBMP-2 solution (i.e. $20 \mu \mathrm{L}$ x $1 \mathrm{mg} / \mathrm{mL}$ ). Following the manufacturer's instructions, the rhBMP-2 solution was applied to the scaffold $20 \mathrm{~min}$ prior to surgical insertion.

\section{Cell viability analysis}

MG-63 cells, a human osteoblastic cell line, were cultured in $\alpha$-MEM supplemented with $10 \%$ foetal bovine serum, $1 \%$ L-glutamine and $2 \%$ penicillin/streptomycin. Media were changed every $4 \mathrm{~d}$ and cells were removed from flasks using trypsin-EDTA solution. Cell number was calculated using a haemocytometer to produce a $3 \times 10^{6}$ cells $/ \mathrm{mL}$ cell suspension.

Drug loaded-PLGA scaffolds (Table 1) were placed in 48 -well plates and seeded with $5 \mu \mathrm{L}$ of a $3 \times 10^{6}$ cells $/ \mathrm{mL}$ cell suspension followed by a 15 min incubation period. The scaffold was then turned over and $5 \mu \mathrm{L}$ of the cell suspension was seeded on the opposite side. This was incubated for a further $15 \mathrm{~min}$. The wells were then flooded with $500 \mu \mathrm{L}$ of standard growth medium. Cell free PLGA scaffolds served as negative controls.

At $3 \mathrm{~d}$ and $7 \mathrm{~d}$ post seeding, cellular viability was assessed using the CellTitre 96 Aqueous One Solution Cell Proliferation Assay kit (Promega, Madison, WI, USA) according to the manufacturer's instructions. Briefly, scaffolds were incubated with the viability solution for 30 min at $37{ }^{\circ} \mathrm{C}$ and read using a spectrophotometer at $595 \mathrm{~nm}$. All samples were assayed in triplicate and the results are representative of $n=6$ scaffolds.

At day 7, cell-scaffolds were stained with fluorescent DAPI (15 min in $0.02 \mu \mathrm{g}, 4$ ',6-DAPI, diamidino-2phenylindole), washed with phosphate-buffered saline (PBS, $10 \mathrm{~min}$ ), and halved transaxially with a stainless steel surgical blade. Representative transaxial scaffold sections were captured with a Leica TCS SP5 confocal microscope (Leica Microsystems, Wetzlar, Germany). DAPI-stained cells were visualised with the $405 \mathrm{~nm}$ laser (emission 410-470 nm) and scaffold autofluorescence was visualised with the $488 \mathrm{~nm}$ laser line of the argon laser (emission $500-570 \mathrm{~nm}$ ). Sections were scanned with a 10x objective using the Tile Scan ( 2 x 5 image array) and the Z-Stack functions (4 sections at $20 \mu \mathrm{m}$ intervals) for a total of 40 images per scaffold. Maximum intensity projections were done with Leica Application Suite Advanced Fluorescence software (Version 2.5.1-6757, Leica Microsystems).

\section{Animal care}

Male Wistar rats were purchased from the Animal Resources Centre (Perth, Australia) and used at 12 weeks (average weight of $440 \mathrm{~g}$ ). Animals were allowed 1-week acclimatisation to local vivarium conditions prior to surgery. Animal studies were approved by the local animal ethics committee (AEC \#5068) and animals were given chow and water ad libitum. 

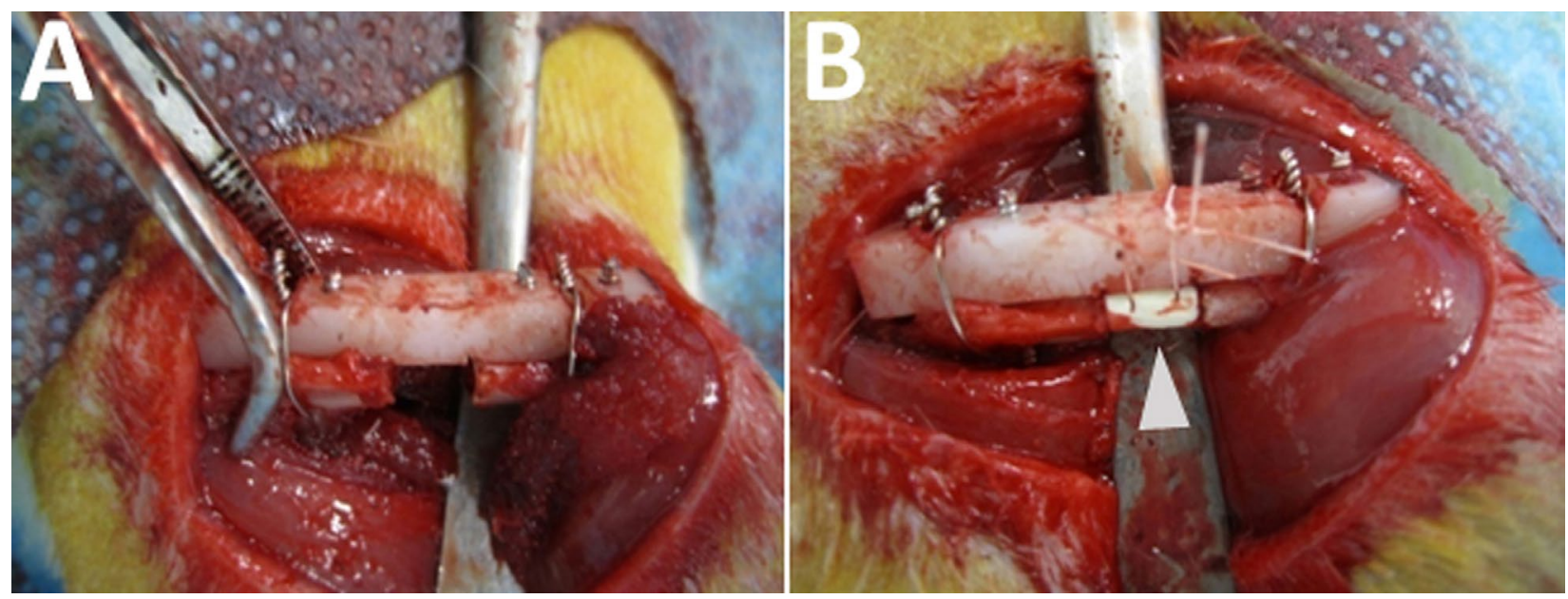

Fig. 1. (A) Fixation of a $6 \mathrm{~mm}$ critical-sized femoral defect with plate and wires, and (B) insertion of a scaffold into the bone defect. Arrowhead points towards a PLGA polymer scaffold.

\section{Surgical insertion of scaffold into rat critical defect}

A well-described rat femoral critical defect model was used (Little et al., 2005). Anaesthesia was induced with an intraperitoneal injection of $75 \mathrm{mg} / \mathrm{kg}$ ketamine and $10 \mathrm{mg} / \mathrm{kg}$ xylazine. A lateral approach to the right femur was made and the periosteum stripped. A polyacetyl plate $(27 \times 4 \times 4 \mathrm{~mm})$ was fixed to the femur with four $1 \mathrm{~mm}$ threaded Kirschner wires and two $1 \mathrm{~mm}$ surgical steel circlage wires passing through pre-fashioned notches in the plate. A $6 \mathrm{~mm}$ critical-sized full-thickness defect was created in the diaphysis with an oscillating saw and the bone was stabilised by the plate (Fig. 1A). The defect was inserted with porous PLGA scaffold loaded with various drug combinations: BMP-2, BMP/ZA, BMP/ZA/HA, or BMP/PS-1145 ( $n=20 /$ scaffold group). As a clinical BMP control, the defect was also inserted with BMP-2 delivered via collagen $(n=20)$. A PLGA scaffold alone group served as a negative control $(n=5)$ (Table 2).

The scaffolds were secured in place by threading two sutures (4/0 Vicryl suture, Ethicon, Sommerville, NJ, USA) through the scaffold's centre and securing the suture around the plate (Fig. 1B). The wound was closed with 4/0 Vicryl suture and $2 \mathrm{~mL}$ sterile saline was given subcutaneously as fluid replacement. Animals were given analgesia with buprenorphine $(0.05 \mathrm{mg} / \mathrm{kg})$ and monitored for pain. Bone repair occurred over the following 6 weeks and rats were monitored by weekly X-ray and weighing. To assess bone formation using fluorochrome labelling, calcein $(10 \mathrm{mg} /$ $\mathrm{kg}$ ) was administered by subcutaneous injection at 10 and $3 \mathrm{~d}$ prior cull. After 6 weeks post-operatively, animals were euthanised and whole femora were harvested post-mortem. Samples were fixed in $4 \%$ paraformaldehyde, and stored in $70 \%$ ethanol for radiographic and histological analysis.

\section{Radiological micro-computed tomography (microCT)}

Three-dimensional (3D) bone measurement was carried out by microCT. Samples were scanned in $70 \%$ ethanol with SkyScan 1174 compact $\mu$ CT scanner (SkyScan, Kontich, Belgium) at $14.7 \mu \mathrm{m}$ pixel resolution and with $0.5 \mathrm{~mm}$ aluminium filter, $50 \mathrm{kV}$ X-ray tube voltage, $800 \mu \mathrm{A}$ tube electric current, and $4500 \mathrm{~ms}$ scanning exposure time. MicroCT images were reconstructed using NRecon (version 1.6.1.7, SkyScan) and three dimensional assessments were conducted with CTAnalyser software (version 1.12.10.3, SkyScan). The primary outcome measurement was bone volume $\left(\mathrm{BV}, \mathrm{mm}^{3}\right)$ of the regenerate using 250 slices that encompassed a $3.712 \mathrm{~mm}$ central region of the defect. The rationale for selecting this region of interest was to minimise variation due to differences in defect height such that a consistent length of regenerate was selected. Notably, scaffold-bone integration at the implant boundaries was independently assessed by means of histology. Secondary outcome measurements included bone tissue alone mineral density (bone TMD, $\mathrm{g} / \mathrm{cm}^{3}$ ). The bone tissue was defined as calcified tissue detected by microCT using a predetermined global threshold set at $0.4 \mathrm{~g} / \mathrm{cm}^{3}$. Bone tissue mineral density (bone TMD, $\mathrm{g} / \mathrm{cm}^{3}$ ) was as defined by Bouxsein et al. (2010) as the material density of bone tissue region only. The total volume of regenerate tissue formed within the critical defect $\left(\mathrm{TV}, \mathrm{mm}^{3}\right)$ was also quantified using microCT. Bone formed outside of the critical defect space relative to the critical defect space was calculated as the excess regenerate $(\%)$.

Bone union grading was further assessed by a single operator blinded to intervention using $3 \mathrm{D}$ maximum intensity projection reconstructions were generated using CTAnalyser software (version 1.12.10.3, SkyScan). Defects were graded as being united (4 cortices in two planes), partially united (2-3 cortices in two planes), or not united.

Samples were excluded by a single operator blinded to intervention as determined by two-dimensional X-ray (27 kV and 2x magnification, MX 20 Digital Camera, Faxitron X-ray Corp, Wheeling, IL, USA) and 3D microCT maximum intensity projections. There were five anaesthetic deaths, two infections, and two cases of loss of fixation due to slipped plates. Eight specimens were excluded due to misalignment of implant with bone ends such that one or both ends of the implant were no longer in the defect. 


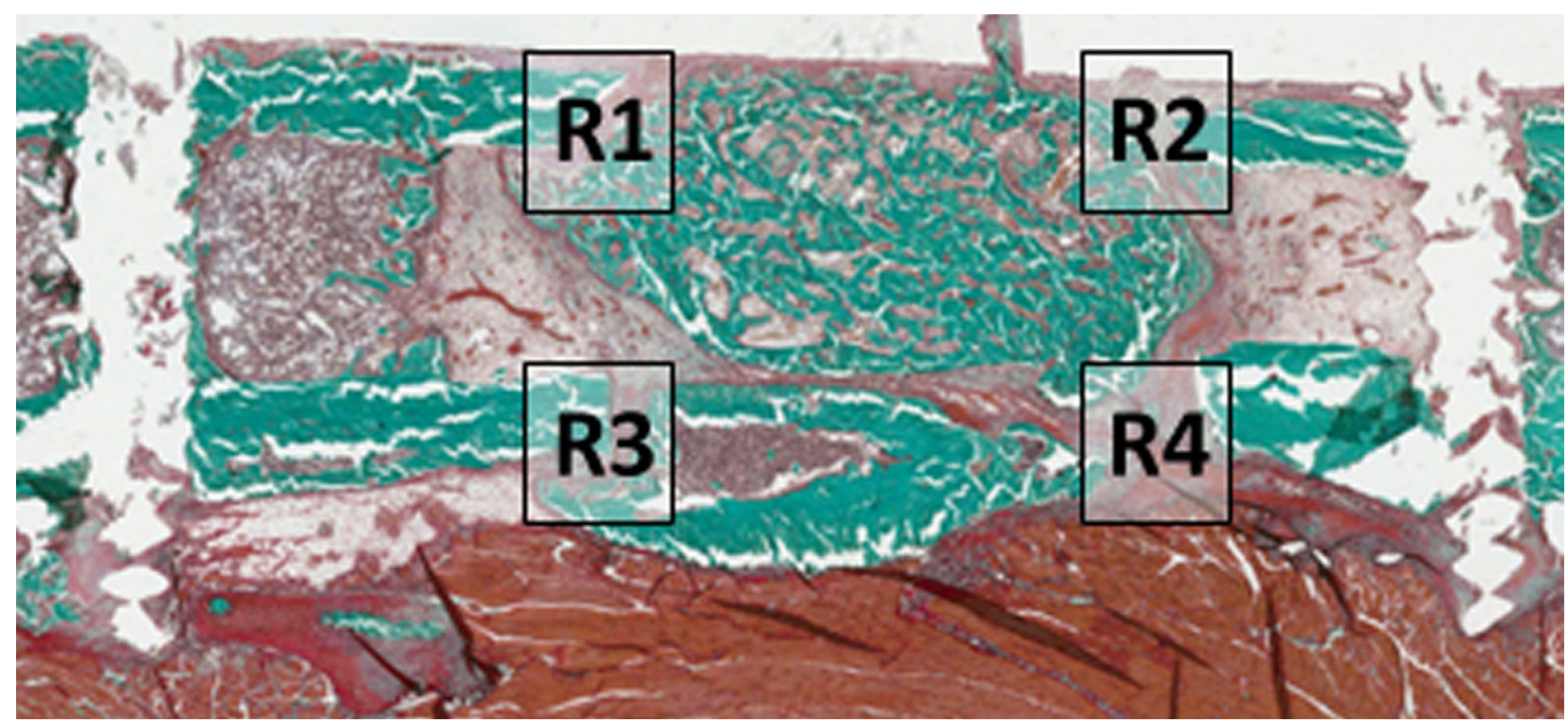

Fig. 2. Representative micrograph illustrating 4 scaffold/cortex regions (R1 to R4) used to assess scaffold integration.

The final group sizes were $n=19(\mathrm{BMP}+\mathrm{COL}), n=17$ $(\mathrm{PLGA}+\mathrm{BMP}), n=15(\mathrm{PLGA}+\mathrm{BMP} / \mathrm{ZA}), n=17(\mathrm{PLGA}$ $+\mathrm{BMP} / \mathrm{ZA} / \mathrm{HA}), n=15(\mathrm{PLGA}+\mathrm{BMP} / \mathrm{PS}-1145)$ and $n=5$ (PLGA only).

\section{Histological analysis}

Histology was conducted on $n=10$ samples for the rhBMP-2 loaded scaffold groups and $n=5$ for the PLGA scaffold control group. Animals were prospectively assigned to histology endpoints prior to surgery. Fixed bone samples were processed and embedded undecalcified in resin for histological sectioning. The right femur of each rat was sliced longitudinally from the middle and serial sections of $0.5 \mu \mathrm{m}$ thick were stained with Von Kossa stain for bone mineral. The integration of regenerate region with ends of the old cortex was assessed on sections stained with Goldner's trichrome. Osteoclasts were identified on sections stained for tartrate-resistant acid phosphatase (TRAP).

Images were captured with a ScanScope digital slide scanner (Aperio Technologies, Inc, Vista, CA, USA), and visualised with ImageScope software (Aperio Technologies). Calcein-flurochrome labelled bone sections were visualised and captured using a Leica TCS SP5 confocal microscope (Leica Microsystems). Calcein-labelled bone was visualised with the $488 \mathrm{~nm}$ line of the argon laser (emission 500-560 nm) and tissue autofluorescence was visualised at $561 \mathrm{~nm}$ (emission 570$670 \mathrm{~nm}$ ) with the DPSS 561 laser. Sections were scanned with a 10x objective using the Tile Scan (200 images) and Z-Stack (5 sections at $10 \mu \mathrm{m}$ steps) functions. Post image processing was done with Leica Application Suite Advanced Fluorescence software (Version 2.5.1-6757, Leica Microsystems).

For each osteointegration analysis, a total of four regions representing the scaffold/cortex interfaces were assessed as illustrated in Fig. 2. The scaffold integration grading system was as follows: 0 points (fibrous tissue, i.e. scaffold not bridged with cortex), 1 point (cartilage, i.e. scaffold partially bridged with cortex), and 2 points (mineralised tissue, i.e. osteoid completely bridged with cortex).

\section{Statistical analyses}

Statistical analysis of microCT data was conducted with non-parametric statistical tests (Kruskal Wallis and Mann Whitney $\mathrm{U}$ ), as process of bone formation and union could not be assumed to follow a normal distribution. Statistical analyses of cell viability data comparison between scaffold groups was conducted with one way ANOVA and post-hoc with Dunnett's $t$-test. Statistical analyses of cell viability data comparison between $3 \mathrm{~d}$ or $7 \mathrm{~d}$ post-seeding within each group was conducted with paired $t$-test. Tests were performed using SPSS Statistics version 21 (SPSS Inc., Chicago, IL, USA). Statistical significance was set at $p<0.05$.

\section{Results}

\section{Cell attachment, proliferation and migration in porous PLGA scaffolds}

To determine the ability of the drug loaded PLGA scaffolds to facilitate MG-63 cell attachment and proliferation, cell viability was determined at days 3 and 7 post seeding. Cell viability was maintained in all scaffold groups at both time points. There were no significant differences in cell viability between any of the scaffold groups at either time point, but between 3 and $7 \mathrm{~d}$ significant cell growth was noted in all groups ( $\mathrm{p}<0.01$, Fig. 3A) indicating the scaffolds were biocompatible. Following $7 \mathrm{~d}$ post seeding, scaffolds were stained with DAPI and examined using confocal microscopy to investigate the distribution of the cells within the scaffolds. DAPI-positive staining was observed in all the scaffold groups. Although cell aggregations formed along the edges of the scaffolds, cells 
Fig. 3. (A) Cell viability of MG-63 seeded onto scaffold at day 3 and day $7 . * p<0.01$ increase $v s$. day 3 (B) MG-63 cell (blue) proliferation through a mid-transaxial plane of a scaffold (green) at day 7. Scale bar $=500 \mu \mathrm{m}$.
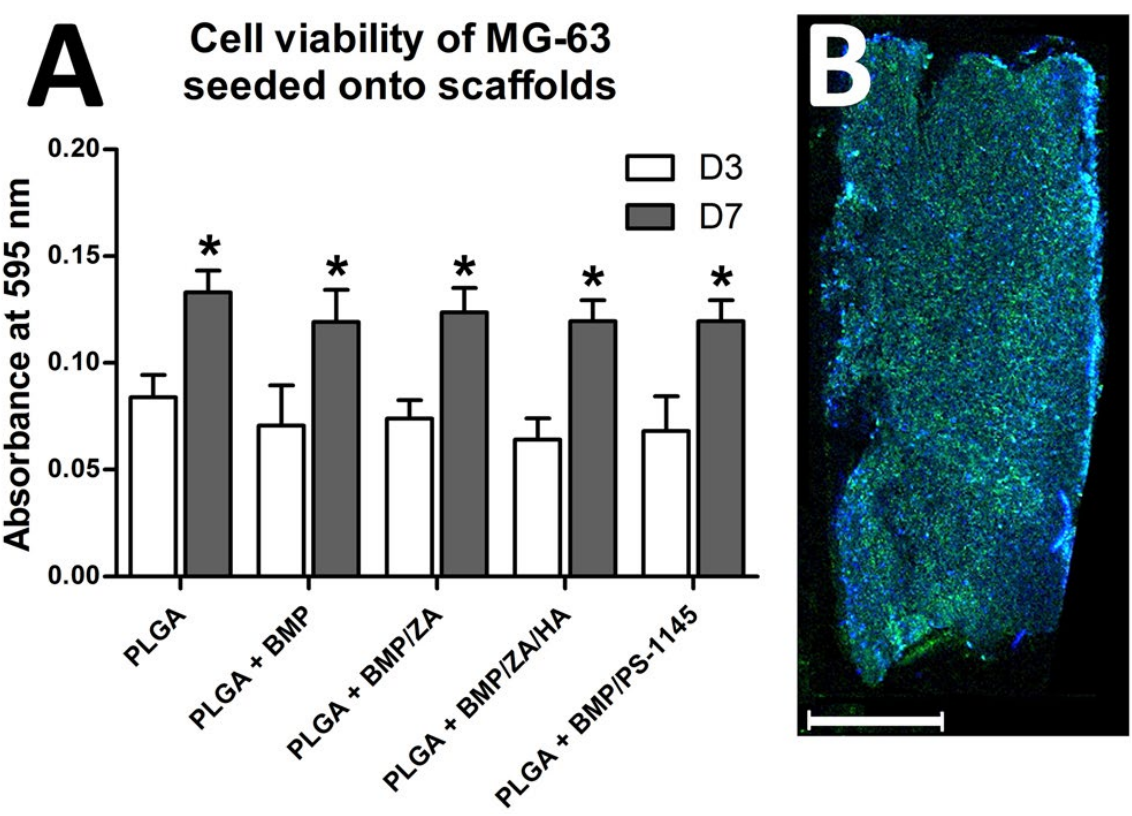

fully penetrated the scaffolds $7 \mathrm{~d}$ post seeding (Fig. 3B). This was observed in all the scaffold types regardless of drug treatment.

\section{D bone healing and bone formation analyses}

3D microCT was used to assess the bone healing-potential of the PLGA scaffolds in a critical-sized bone defect. The union rate was assessed by a single operator blinded to intervention. The region of interest assessed for the union rate included $3 \mathrm{D}$ microCT reconstructions of the regenerate region and surrounding cortices. Bone formation in the regenerate region was quantified by bone volume $(\mathrm{BV}$, $\mathrm{mm}^{3}$ ) and bone tissue alone mineral density (bone TMD, $\mathrm{g} / \mathrm{cm}^{3}$ of calcium hydroxyapatite).

$3 \mathrm{D}$ microCT reconstructions of the regenerate and surrounding cortices were used to assess the union rate. The highest union rate was found with PLGA + BMP/ ZA/HA co-treatment (94\% complete unions), followed by PLGA + BMP/PS-1145 co-treatment ( $87 \%$ complete unions). BMP delivery via COL and PLGA systems led to $68 \%$ and $53 \%$ complete unions, respectively. Finally, PLGA + BMP/ZA led to $47 \%$ complete unions (Fig. 4).

$3 \mathrm{D}$ bone formation was quantified by bone volume $\left(\mathrm{BV}, \mathrm{mm}^{3}\right)$ and bone tissue mineral density (bTMD, $\mathrm{g} / \mathrm{cm}^{3}$ ) at the regenerate region (Fig. 5). Local BMP/ZA/HA cotreatment significantly increased bone volume over PLGA + BMP control $(+78.18 \%, p<0.01)$ and was comparable to $\mathrm{COL}+\mathrm{BMP}$ control $(+20.16 \%, p=0.27)$ (Fig. 5A). However, local BMP/ZA did not significantly change bone volume compared to PLGA + BMP control $(+16.96 \%$, $p=0.56)$ and showed significantly lower bone volume compared to COL + BMP control $(-21.13 \%, p=0.046)$. Local BMP/PS-1145 co-treatment significantly increased bone volume compared to PLGA + BMP control (52.0\%, $p=0.01)$, but not when compared to COL + BMP control $(+2.49 \%, p=0.62)$. Finally, COL + BMP had higher bone volume compared to PLGA + BMP $(+48.3 \%, p<0.01)$.

The $3 \mathrm{D}$ bone tissue mineral density (bTMD, g/ $\mathrm{cm}^{3}$ ) was assessed at the regenerate region (Fig. 5B). Compared

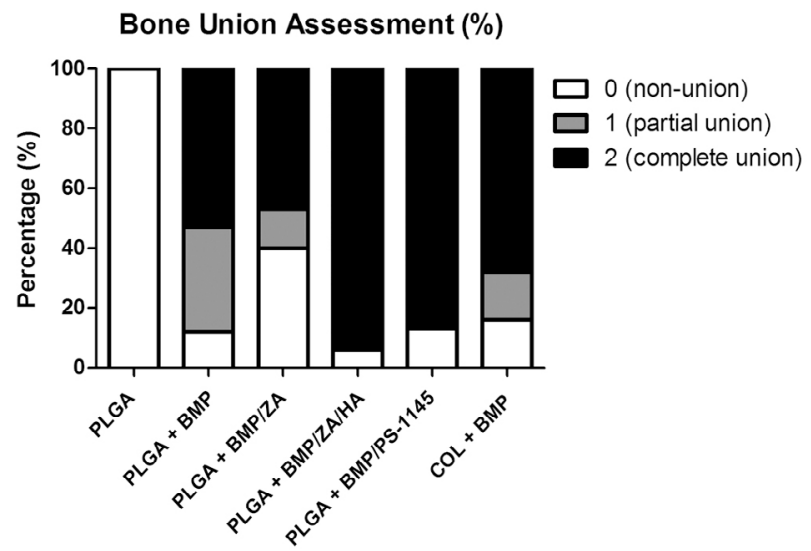

Fig. 4. Radiographic assessment of bone union at 6 weeks.

with COL + BMP, regenerate bone density was higher in local PLGA + BMP treatment $(+4.94 \%, p=0.04)$ and co-treatment with ZA or ZA/HA $(+8.45 \%, p=0.03$ and $+9.12 \%, p<0.01)$. Local co-treatment with PLGA + BMP/ PS-1145 led to comparable bone density to COL + BMP.

Three-dimensional spatial control of bone formation $2 \mathrm{D}$ and $3 \mathrm{D}$ microCT reconstructions of the regenerate region and the adjacent original cortex were generated to visually compare implant-interface boundary and the production of bone outside the original scaffold template (Fig. 6). Defects treated with PLGA scaffold in the absence of rhBMP-2 did not induce bone formation and were thus graded as having no integration.

The microCT reconstructions demonstrated greater restriction of rhBMP-2-induced bone formation in the porous PLGA scaffold groups as illustrated by coronal 2D slices (Fig. 6A) and 3D maximum intensity projection reconstructions (Fig. 6B coronal and Fig. 6C transaxial). MicroCT quantification confirmed PLGA scaffold led to a greater spatial control of rhBMP-2-induced bone, with a significantly lower regenerate tissue volume $\left(\mathrm{TV}, \mathrm{mm}^{3}\right)$ over COL + BMP treatment, $(-65.9 \% \mathrm{TV}, p<0.01)$. In 

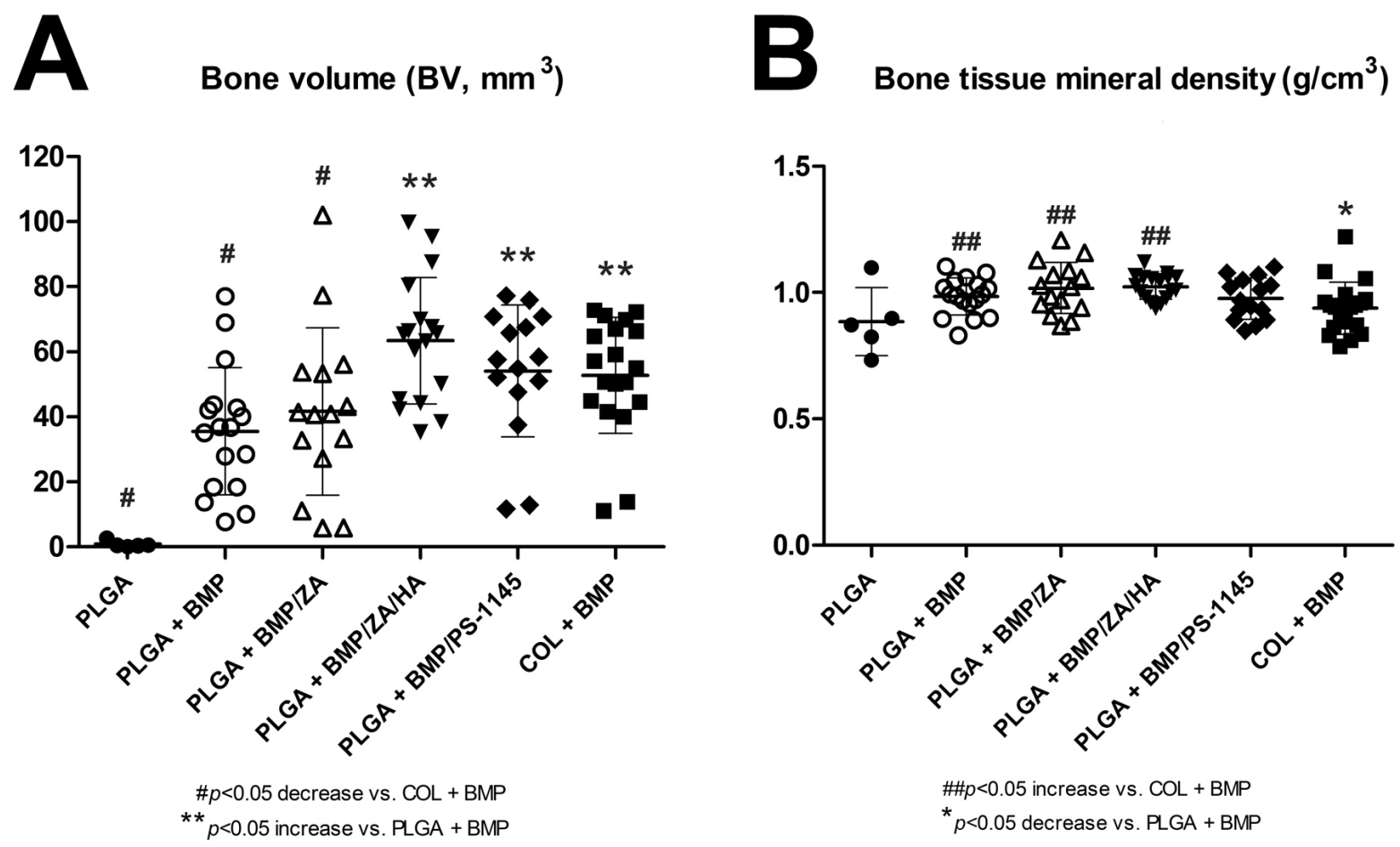

Fig. 5. Bone formation analysis at regenerate region measured at 6 weeks post-operatively. (A) Bone volume (BV, $\mathrm{mm}^{3}$ ) and $(\mathbf{B})$ bone tissue mineral density (bone TMD, $\mathrm{g} / \mathrm{cm}^{3}$ ). $\# p<0.05$ decrease $v s . \mathrm{COL}+\mathrm{BMP}$, \# $p<0.05$ increase vs. COL + BMP, ${ }^{*} p<0.05$ decrease $v s$. PLGA + BMP, ${ }^{* *} p<0.05$ increase $v s$. PLGA + BMP.

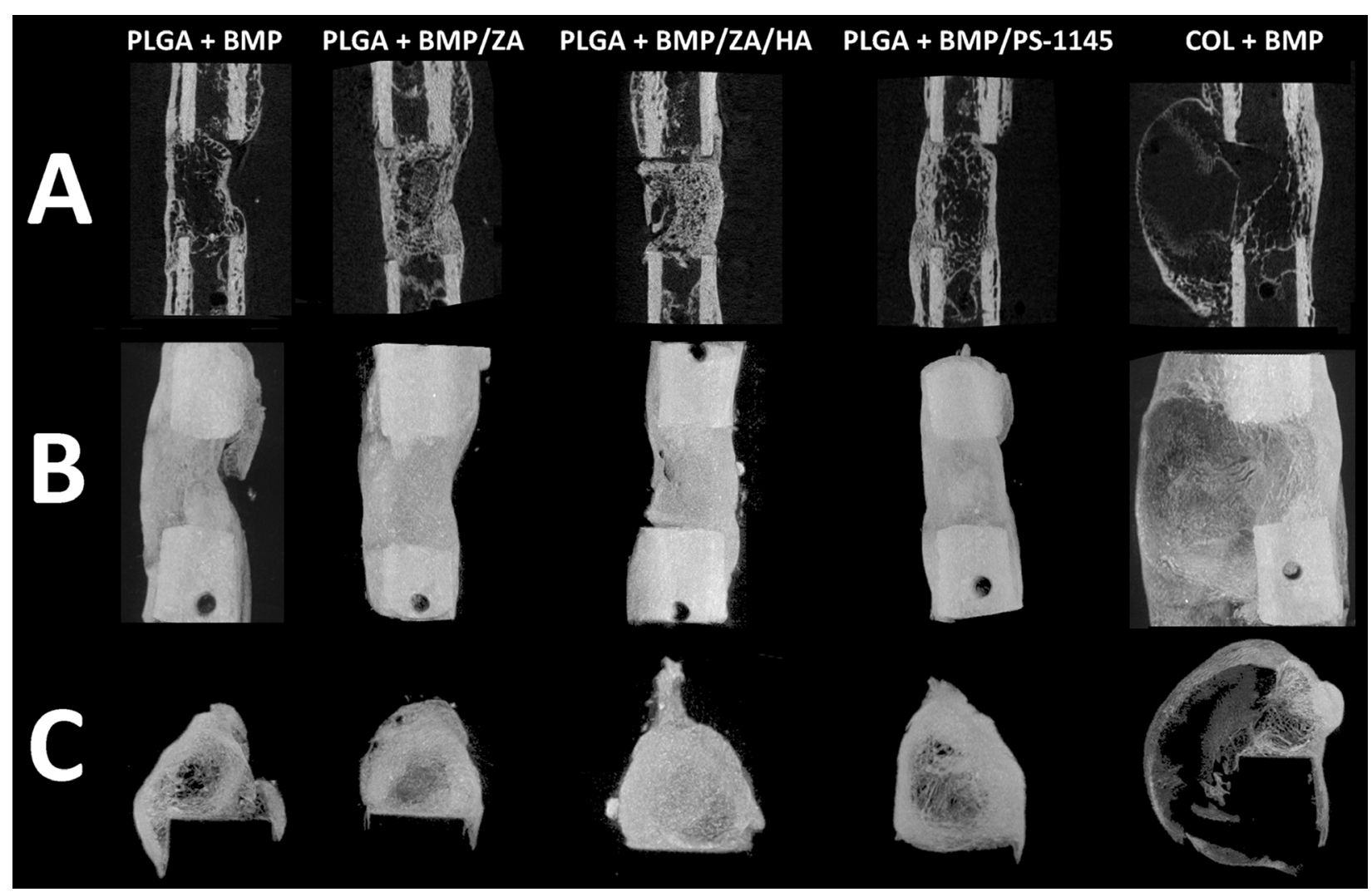

Fig. 6. Reconstructions of healed critical-sized defects at 6-weeks post-operatively. The cortex and regenerate are shown as (A) 2D coronal slices and (B) 3D reconstructions. The regenerate region is shown as (C) 3D reconstructions. 
A

Tissue volume (TV, $\mathrm{mm}^{3}$ )

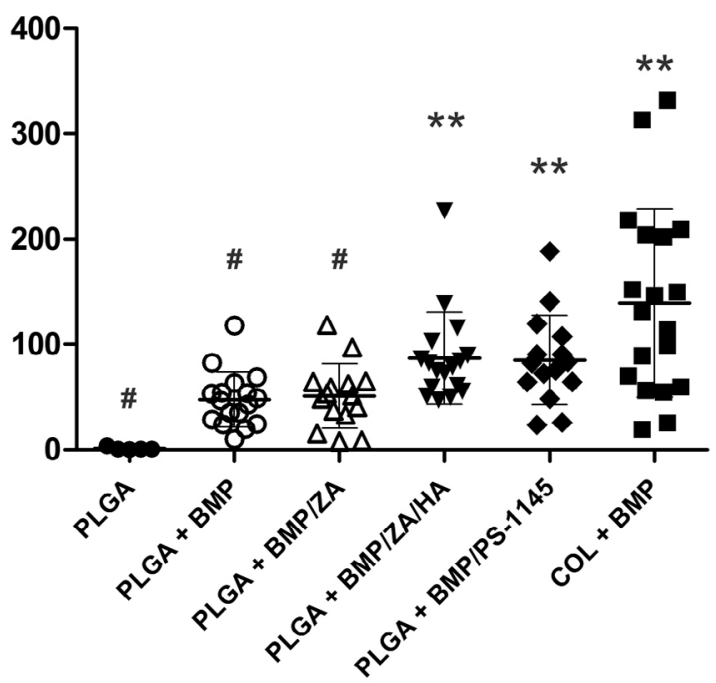

$\# p<0.01$ decrease vs. $\mathrm{COL}+\mathrm{BMP}$

${ }^{* *} p<0.01$ increase vs. PLGA + BMP

\section{Excess regenerate region \%}

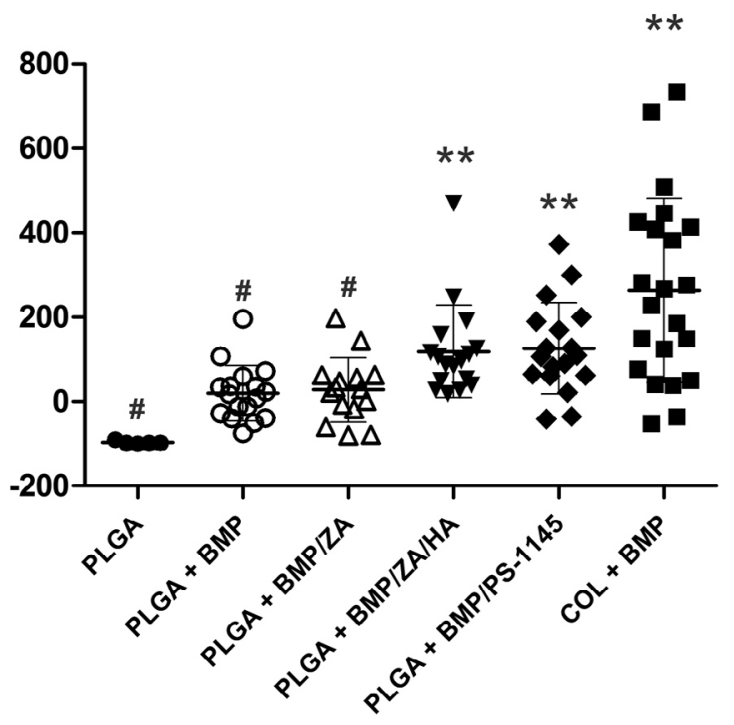

$\# p<0.01$ decrease vs. $\mathrm{COL}+\mathrm{BMP}$

${ }^{* *} p<0.01$ increase vs. PLGA + BMP

Fig. 7. Regenerate region spatial control measured at 6 weeks post-operatively. (A) Regenerate tissue volume (TV, $\mathrm{mm}^{3}$ ) and (B) excess regenerate percentage (\%). $\# p<0.01$ decrease $v s$. COL + BMP and ${ }^{* *} p<0.01$ decrease $v s$. PLGA + BMP.
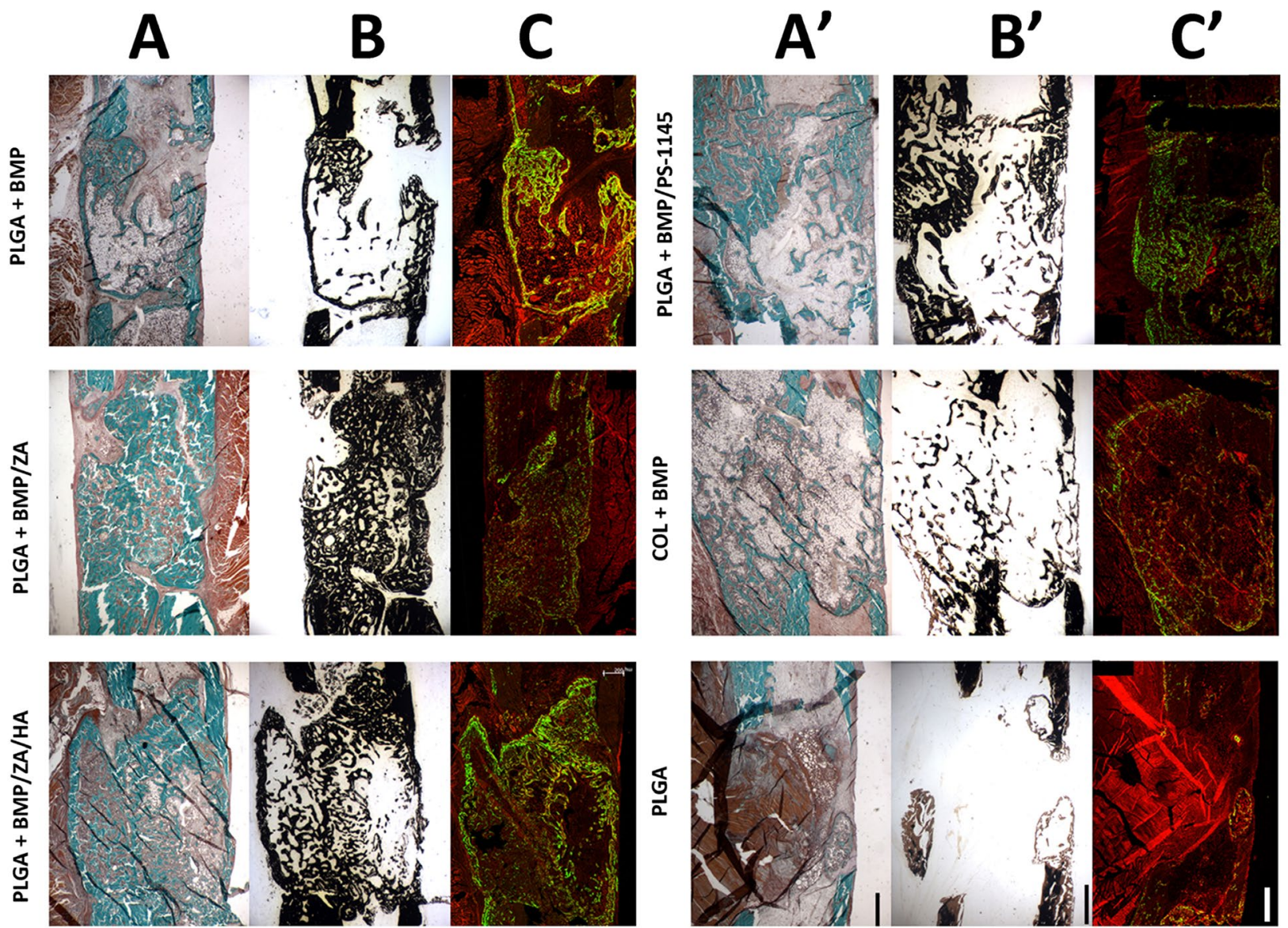

Fig. 8. Representative micrographs of bone defects at 6-weeks. (A and $\mathbf{A}^{\prime}$ ) Goldner's Trichrome-stained sections, (B and $\mathbf{B}^{\prime}$ ) von Kossa-stained sections, and ( $\mathbf{C}$ and $\mathbf{C}^{\prime}$ ) calcein (green) labelling performed at 10 and $3 \mathrm{~d}$ prior to end of study. Scale bar $=1 \mathrm{~mm}$. 
some cases, this led to an apparently inferior implantinterface osseointegration compared to collagen, and this was further explored in histological sections. Images shown represent specimens closest to the mean BV for each treatment group.

As an alternate measure of spatial control, the tissue volume of the regenerate $\left(\mathrm{TV}, \mathrm{mm}^{3}\right)$, was quantified by microCT. The rhBMP-2-induced bone was compared between PLGA and COL local delivery systems. The excess regenerate as a percentage of the defect space was considerably greater in the collagen group compared to the PLGA groups (Fig. 7).

\section{Histology}

Histological slices of the regenerate and cortex were stained with Goldner's trichrome and von Kossa to visualise mineralised bone matrix (Fig. 8). Calcein fluorochrome-labelled bone was used to compare the bone retention/turnover with PLGA + BMP/anti-resorptive cotreatment with COL + BMP. Increased mineralised bone matrix of regenerate region was shown in PLGA + BMP/ $\mathrm{ZA} \pm \mathrm{HA}$ group compared with BMP delivered via collagen or via PLGA (Figs. 8A and B). Defects treated with BMP/ PS-1145 co-treatment also showed increased bone density of regenerate compared with BMP + PLGA treatment. Finally, calcein fluorochrome-labelled bone showed greater labelling (i.e. higher bone retention) in PLGA + BMP/ZA/ HA treated defects compared with PLGA + BMP/antiresorptives (ZA or PS-1145) and COL + BMP (Fig. 8C), indicating lower bone turnover in PLGA + BMP/ZA/HA compared to other treatment groups.

Goldner's trichrome-stained samples were used to assess the scaffold-implant integration using a scoring system for the four cortices in two planes. There was a trend towards reduced integration at the interface with rhBMP-2 and rhBMP-2/ZA PLGA groups versus collagen delivery, however, the trend was not significant ( $p=0.49$ and $p=0.39$, respectively). The rhBMP-2/PS1145 and rhBMP-2/ZA/HA groups were comparable to collagen (Fig. 9). Statistical analyses showed that only the rhBMP-2/ ZA/HA group showed significantly greater integration than rhBMP-2 PLGA controls $(p=0.02)$. While rhBMP-2/ PS1145 showed a trend towards increased integration versus rhBMP, it did not reach significance ( $p=0.26$ vs $\mathrm{COL}+\mathrm{rhBMP}$ ) with a post-hoc power analysis indicating the potential for type II error.

\section{Discussion}

The healing of critical-sized defects is often complicated by premature and/or excessive bone resorption caused by stress-shielding, instability, or inflammation/infection (Amanat et al., 2005). These challenges associated with resorption can be aggravated by rhBMP treatments, which can promote osteoclastic resorption (Itoh et al., 2001; Kaneko et al., 2000; Pradhan et al., 2006). Thus numerous pre-clinical studies have investigated the efficacy of modulating rhBMP-induced bone formation with adjunct anti-resorptive agents, such as bisphosphonates (Belfrage et al., 2011; Chen et al., 2004; Chen et al., 2006; Jakobsen

\section{Scaffold integration grade (out of 8)}

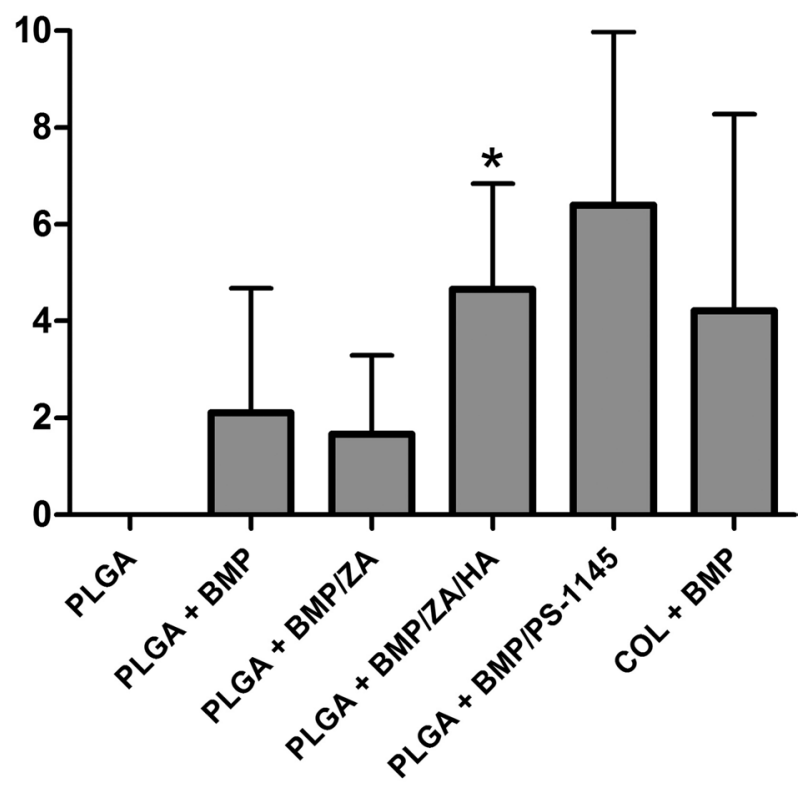

Fig. 9. The average scaffold/cortex integration grades at 6 weeks post-operatively. $* p=0.02 v s$. PLGA + BMP.

et al., 2007; Jakobsen et al., 2010; Jeppsson et al., 2003; Little et al., 2005; Yu et al., 2010b; Yu et al., 2013). IKK inhibitors such as PS-1145 also show promise for maximising rhBMP-induced bone formation (Carr et al., 2011).

Incorporation of small molecule inhibitors of bone resorption into classical collagen scaffolds can be challenging. Acellular collagen scaffolds are able to bind and retain BMPs, although there is still a significant burst release. A recent systematic clinical review (Carragee et al., 2011) emphasised the limitations of rhBMP delivery via collagen, including poorly controlled and ectopic bone formation. Moreover, the review highlighted the potential benefits of modulating the rhBMP delivery rate using alternate carriers (Carragee et al., 2011). In light of the limitations of porous collagen, there has been previous research in this area (Brown et al., 2011; DeLustro et al., 1990; Geesink et al., 1999; Kato et al., 2006; Olsen et al., 2003).

We have previously utilised this porous PLGA scaffold as an alternative local rhBMP delivery system able to codeliver anti-resorptives in simple ectopic bone formation model (Yu et al., 2013). In this study, we demonstrated superior rhBMP-2 induced bone formation with local adjunct anti-resorptive ZA adsorbed HA microparticles, when compared with PLGA + BMP-2 and PLGA + BMP-2/ZA. Compared to the clinical gold standard of collagen, PLGA scaffolds showed a delayed rhBMP-2 in vitro release profile. Moreover, the adsorption of ZA onto HA microparticles further reduced ZA release from PLGA scaffolds without altering rhBMP-2 release.

In light of these data, this study aimed to employ a more complex and clinically-relevant rat femoral criticalsized defect surgical model. It first aimed to demonstrate 
the efficacy of a porous PLGA biodegradable scaffold as an alternative rhBMP delivery system with greater spatial control of new bone formation. Secondly, this study aimed to further modulate PLGA + rhBMP scaffold-induced critical-sized defect healing with local adjunct antiresorptive agents, zoledronic acid (ZA) or IKK-inhibitor (PS-1145).

The porous PLGA scaffold presented in this study facilitated greater spatial control of rhBMP-induced bone formation over clinically used collagen scaffold. This is most obvious in radiographic images/microCT reconstructions where the COL control group showed new bone that formed considerably away from the original cortex. While the volume of the regenerate in the COL group was considerably greater, the measured bone volume was only $\sim 50 \%$ higher, and histology showed the COL group to be filled with a substantive pseudo marrow cavity. In contrast, the PLGA scaffold showed a higher density and more trabecular-like bone (Fig. 8). The mechanism for this more restricted control may be associated with the altered release rate of rhBMPs, which has been previously shown comparing this PLGA implant to collagen (Yu et al., 2013). Development of this system may allow for reduced clinical complications associated with uncontrolled bone formation, including unwanted ossification of the surrounding tissues and neural impingement (Carragee et al., 2011). In addition, with specialised mould geometry, bone of customized shapes and sizes might be generated.

The co-delivery of anti-resorptives and/or ceramic microparticles led to significant increases in union rate and in bone volume. This is consistent with our prior findings showing enhancement of rhBMP-2 action with bisphosphonates in an ectopic bone model using this PLGA carrier (Yu et al., 2013). The doses selected for this critical defect study were comparable in terms of drug concentration per unit scaffold with this prior study, although the implant size was larger. The addition of antiresorptive drugs did not adversely affect osteoblastic cells in vitro in terms of viability or migration into the implants. Moreover, while the breakdown products of PLGA are acidic and have the potential to cause inflammation, there was no histological evidence of inflammation or fibrosis. In addition, the integration rate with the surrounding cortex was significantly improved with anti-resorptive treatment.

Local and systemic bisphosphonates are reported to reduce TRAP-positive cell numbers (Yu et al., 2010b) and this was also observed in the critical defect model. A group containing both bisphosphonate and HA particles was included as bisphosphonates have an affinity for calcium phosphate. This approach has been previously shown to delay ZA release (Yu et al., 2013). New insight has been obtained regarding the synergy between HA and bisphosphonate from a recent study using an alternative injectable delivery system. In this system HA microparticles were found to sequester bisphosphonate and delay its release. Moreover, in a cell culture model, the addition of HA microparticles provided cytoprotective effects against high dose bisphosphonate (Cheng et al., 2013). Pharmacological inhibition with PS-1145 demonstrates the potential use of IKK inhibitors as alternative anti-resorptive agents. IKK inhibition has been shown to suppress premature resorption in the repair of large bony defects through the inhibition of pathways necessary for osteoclast survival, differentiation, and function (von Metzler et al., 2007). Combined with our recent results in an ectopic bone model (Carr et al., 2011), this study demonstrated further the utility of this agent in a more challenging defect model.

One perceived limitation noted in this model was that the spatial control of bone formation was in some cases associated with poorer scaffold/cortex integration. This underlies reduced bone union in the PLGA + BMP group. We propose that a longer scaffold height that could be press fit to the defect would facilitate better integration between the PLGA implant and the original cortex. This, in combination with additional suturing to secure the implant further, could also reduce the rate of implant misalignment. Alternatively, we could envision a design where a cylinder slightly longer than the defect could be wrapped around the defect creating a region of overlap. One key advantage of a PLGA local delivery system is the capacity for increased control over the shape of the engineered bone by implanting custom-moulded scaffolds. Similar custom-shaping scaffold systems have been demonstrated with metal meshed scaffolds (Warnke et al., 2004) and polymer/collagen hybrid sheet-based scaffolds (Tsuchiya et al., 2004).

\section{Conclusion}

This study demonstrated for the first time, the efficacy of using porous PLGA scaffold co-delivering rhBMP/ZA/ HA or rhBMP-2/PS-1145 to enhance rat critical defect healing. The synergistic anabolic and anti-resorptive effects of the local delivery system showed the potential to reduce the effective rhBMP-2 dose and to avoid the adverse events associated with local high rhBMP-2 doses. Furthermore, incorporation of hydroxyapatite microparticles demonstrated a potential to augment the effects of ZA, and to lower the effective ZA drug dose required. Finally, this study demonstrated the efficacy of using porous PLGA scaffold for better spatial control of rhBMP-induced defect healing over collagen scaffold.

\section{Acknowledgements}

Nicole Y.C. Yu received salary support from the Australian National Health \& Medical Research Council (NHMRC) Grant APP1020987. Aaron Schindeler received salary support from NHMRC Project Grant APP1003478. This work was supported by NHMRC Project Grant APP 1020987 and in part by ARC Discovery Grant DP110104446. The Leica SP5 in the CLEM Suite at KRI was supported by the following grants: Cancer Institute New South Wales Research Equipment (10/REG/123), NHMRC (2009-02759), the Ian Potter Foundation (20100508), the Perpetual Foundation (730), Ramaciotti Foundation (3037/2010), and the Sydney Medical School Research Infrastructure Major Equipment Scheme. MG-63 cells were a gift from Professor Rebecca Masson from the University of Sydney. 


\section{References}

Amanat N, Brown R, Bilston LE, Little DG (2005) A single systemic dose of pamidronate improves bone mineral content and accelerates restoration of strength in a rat model of fracture repair. J Orthop Res 23: 1029-1034.

Belfrage O, Flivik G, Sundberg M, Kesteris U, Tägil M (2011) Local treatment of cancellous bone grafts with BMP-7 and zoledronate increases both the bone formation rate and bone density. Acta Orthop 82: 228-233.

Bouxsein ML, Boyd SK, Christiansen BA, Guldberg RE, Jepsen KJ, Müller R (2010) Guidelines for assessment of bone microstructure in rodents using micro-computed tomography. J Bone Miner Res 25: 1468-1486.

Brown KV, Li B, Teja G, Perrien DS, Guelcher SA, Wenke JC (2011) Improving bone formation in a rat femur segmental defect by controlling bone morphogenetic protein-2 release Tissue Eng Part A 17: 1735-1746.

Calandrelli L, Immirzi B, Malinconico M, Luessenheide S, Passaro I, Pasquale R, Oliva A (2004) Natural and synthetic hydroxyapatite filled PCL: mechanical properties and biocompatibility analysis. J Bioact Compat Polym 19: 301-313.

Cao Y, Croll TI, Cooper-White JJ, O’Connor AJ, Stevens GW (2004a) Production and surface modification of polylactide-based polymeric scaffolds for soft tissue engineering. In: Hollander AP, Hatton PV (eds) Biopolymer Methods in Tissue Engineering, Humana Press, Totowa, NJ, pp 87-111.

Cao Y, Davidson MR, O'Connor AJ, Stevens GW, Cooper-White JJ (2004b) Architecture control of three-dimensional polymeric scaffolds for soft tissue engineering. I. Establishment and validation of numerical models. J Biom Mater Res Part A 71A: 81-89.

Carr D, Yu N, Fitzpatrick J, Peacock L, Mikulec K, Ruys A, Cooper-White J, Little D, Schindeler A (2011) Synergy between rhBMP-2 and IKK-inhibitor PS-1145 delivered via a porous biodegradable polymer implant. J Tissue Sci Eng S1: 003.

Carragee EJ, Hurwitz EL, Weiner BK (2011) A critical review of recombinant human bone morphogenetic protein-2 trials in spinal surgery: emerging safety concerns and lessons learned. Spine J 11: 471-491.

Chen W-J, Jingushi S, Hirata G, Matsumoto Y, Iwamoto Y (2004) Intramuscular bone inducation by the simultaneous administration of recombinant human bone morphogenetic protein 2 and bisphosphonate for autobone graft. Tissue Eng 10: 1652-1661.

Chen W-J, Jingushi S, Jingushi K, Iwamoto Y (2006) In vivo banking for vascularized autograft bone by intramuscular inoculation of recombinant human bone morphogenetic protein-2 and $\beta$-tricalcium phosphate. J Orthop Sci 11: 283-288.

Cheng T, Valtchev P, Murphy C, Cantrill L, Dehghani F, Little D, Schindeler A (2013) A sugar-based phasetransitioning delivery system for bone tissue engineering. Eur Cell Mater 26: 208-221.

Coathup MJ, Blunn GW, Flynn N, Williams C, Thomas NP (2001) A comparison of bone remodelling around hydroxyapatite-coated, porous-coated and grit-blasted hip replacements retrieved at post-mortem. J Bone Joint Surg Br 83: 118-123.

DeLustro F, Dasch J, Keefe J, Ellingsworth L (1990) Immune responses to allogeneic and xenogeneic implants of collagen and collagen derivatives. Clin Orthop Relat Res 260: 263-279.

Geesink RGT, Hoefnagels NHM, Bulstra SK (1999) Osteogenic activity of OP-1 bone morphogenetic protein (BMP-7) in a human fibular defect. J Bone Joint Surg Br 81: 710-718.

Giannoudis PV, Einhorn TA, Marsh D (2007) Fracture healing: The diamond concept. Injury 38 Suppl 4: S3-6.

Hollister SJ (2005) Porous scaffold design for tissue engineering. Nat Mater 4: 518-524.

Idris AI, Libouban H, Nyangoga H, Landao-Bassonga E, Chappard D, Ralston SH (2009) Pharmacologic inhibitors of I $\mathrm{B}$ kinase suppress growth and migration of mammary carcinosarcoma cells in vitro and prevent osteolytic bone metastasis in vivo. Mol Cancer Ther 8: 2339-2347.

Idris AI, Krishnan M, Simic P, Landao-Bassonga E, Mollat P, Vukicevic S, Ralston SH (2010) Small molecule inhibitors of $\mathrm{I} \kappa \mathrm{B}$ kinase signaling inhibit osteoclast formation in vitro and prevent ovariectomy-induced bone loss in vivo. FASEB J 24: 4545-4555.

Itoh K, Udagawa N, Katagiri T, Iemura S, Ueno N, Yasuda H, Higashio K, Quinn JMW, Gillespie MT, Martin TJ, Suda T, Takahashi N (2001) Bone morphogenetic protein 2 stimulates osteoclast differentiation and survival supported by receptor activator of nuclear factor-kB ligand. Endocrinology 142: 3656-3662.

Jakobsen T, Baas J, Bechtold JE, Elmengaard B, Soballe K (2007) Soaking morselized allograft in bisphosphonate can impair implant fixation. Clin Orthop Relat Res 463: 195-201.

Jakobsen T, Baas J, Bechtold J, Elmengaard B, Søballe K (2010) The effect of soaking allograft in bisphosphonate: A pilot dose-response study. Clin Orthop Relat Res 468: 867-874.

Jeppsson C, Åstrand J, Tägil M, Aspenberg P (2003) A combination of bisphosphonate and BMP additives in impacted bone allografts Acta Orthop Scand 74: 483-489.

Kaneko H, Arakawa T, Mano H, Kaneda T, Ogasawara A, Nakagawa M, Toyama Y, Yabe Y, Kumegawa M, Hakeda Y (2000) Direct stimulation of osteoclastic bone resorption by bone morphogenetic protein (BMP)-2 and expression of BMP receptors in mature osteoclasts. Bone 27: 479-486.

Kato M, Toyoda H, Namikawa T, Hoshino M, Terai H, Miyamoto S, Takaoka K (2006) Optimized use of a biodegradable polymer as a carrier material for the local delivery of recombinant human bone morphogenetic protein-2 (rhBMP-2). Biomaterials 27: 2035-2041.

Little D, McDonald M, Bransford R, Godfrey C, Amanat N (2005) Manipulation of the anabolic and catabolic responses with OP-1 and zoledronic acid in a rat critical defect model. J Bone Miner Res 20: 2044-2052.

Maquet V, Boccaccini AR, Pravata L, Notingher I, Jérôme R (2003) Preparation, characterization, and in vitro degradation of bioresorbable and bioactive composites 
based on Bioglass ${ }^{\circledR}$-filled polylactide foams. J Biomed Mater Res A 66: 335-346.

Maquet V, Boccaccini AR, Pravata L, Notingher I, Jérôme R (2004) Porous poly(a-hydroxyacid)/Bioglass ${ }^{\circledR}$ composite scaffolds for bone tissue engineering. I: Preparation and in vitro characterisation. Biomaterials 25: 4185-4194.

Mooney DJ, Kaufmann PM, Sano K, McNamara KM, Vacanti JP, Langer R (1994) Transplantation of hepatocytes using porous, biodegradable sponges. Transplant Proc 26: 3425-3426.

Olsen D, Yang C, Bodo M, Chang R, Leigh S, Baez J, Carmichael D, Perälä M, Hämäläinen E, Jarvinen M, Polarek J (2003) Recombinant collagen and gelatin for drug delivery. Adv Drug Deliv Rev 55: 1547-1567.

Pradhan B, Bae H, Dawson E, Patel V, Delamarter R (2006) Graft resorption with the use of bone morphogenetic protein: lessons from anterior lumbar interbody fusion using femoral ring allografts and recombinant human bone morphogenetic protein-2. Spine 31: E377-384.

Rezwan K, Chen QZ, Blaker JJ, Boccaccini AR (2006) Biodegradable and bioactive porous polymer/ inorganic composite scaffolds for bone tissue engineering. Biomaterials 27: 3413-3431.

Ruocco MG, Maeda S, Park JM, Lawrence T, Hsu L-C, Cao Y, Schett G, Wagner EF, Karin M (2005) IкB kinase (IKK) $\beta$, but not IKK $\alpha$, is a critical mediator of osteoclast survival and is required for inflammation-induced bone loss. J Exp Med 201: 1677-1687.

Russell R, Xia Z, Dunford J, Oppermann U, Kwaasi A, Hulley P, Kavanagh K, Triffitt J, Lundy M, Phipps R (2007) Bisphosphonates: an update on mechanisms of action and how these relate to clinical efficacy. Ann N Y Acad Sci 1117: 209-257.

Ruys AJ, Sorrell CC, Brandwood A, Milthorpe BK (1995) Hydroxyapatite sintering characteristics: correlation with powder morphology by high-resolution microscopy. J Mater Sci Lett 14: 744-747.

Sokolsky-Papkov M, Agashi K, Olaye A, Shakesheff K, Domb AJ (2007) Polymer carriers for drug delivery in tissue engineering. Adv Drug Deliv Rev 59: 187-206.

Tsuchiya K, Mori T, Chen G, Ushida T, Tateishi T, Matsuno T, Sakamoto M, Umezawa A (2004) Customshaping system for bone regeneration by seeding marrow stromal cells onto a web-like biodegradable hybrid sheet. Cell Tissue Res 316: 141-153.

von Metzler I, Krebbel H, Hecht M, Manz RA, Fleissner C, Mieth M, Kaiser M, Jakob C, Sterz J, Kleeberg L, Heider U, Sezer O (2007) Bortezomib inhibits human osteoclastogenesis. Leukemia 21: 2025-2034.

Warnke PH, Springer ING, Wiltfang J, Acil Y, Eufinger H, Wehmöller M, Russo PAJ, Bolte H, Sherry E, Behrens E, Terheyden H (2004) Growth and transplantation of a custom vascularised bone graft in a man. Lancet 364: 766-770.

Wolff J (1892) Das gasetz der transformation der knochen [The law of bone remodelling]. Verlag von August Hirschwald, Berlin.

Yu NYC, Schindeler A, Little DG, Ruys AJ (2010a) Biodegradable poly(alpha-hydroxy acid) polymer scaffolds for bone tissue engineering. J Biomed Mater Res B Appl Biomater 93: 285-295.

Yu NYC, Schindeler A, Peacock L, Mikulec K, Baldock PA, Ruys AJ, Little DG (2010b) In vivo local co-delivery of recombinant human bone morphogenetic protein-7 and pamidronate via poly-D, L-lactic acid. Eur Cell Mater 20: 431-442.

Yu NYC, Schindeler A, Tägil M, Ruys A, Little D (2012) Use of BMPs and bisphosphonates in improving bone fracture healing. Front Biosci (Elite Ed) 4: 26472653.

Yu NYC, Schindeler A, Peacock L, Mikulec K, Fitzpatrick J, Ruys A, Cooper-White JJ, Little DG (2013) Modulation of anabolic and catabolic responses via a porous polymer scaffold manufactured using thermally induced phase separation. Eur Cell Mater 25: 190-203.

\section{Discussion with Reviewers}

Reviewer I: The most interesting finding appears to be the spatial control. How would you quantify that?

Authors: Spatial control is a broad term that encompasses the overall size of the regenerate (TV), descriptive illustration of the shape of the regenerate, and the integration of the regenerate with the original cortex. All of these methods are commonly reported for characterising a regenerate or fracture callus. Design of a novel metric for measuring spatial control is complex and would be open to debate. One potential quantifiable method would be to measure any regenerate tissue that extends beyond the original cortex in terms of a tissue volume (TV) amount. A more simplistic streamlined method is to simply take the existing regenerate TV values and subtract a cylindrical area equal to $\pi R^{2} H$ where $R$ is half the average of the diameters at both ends of the bone defect and $\mathrm{H}$ is the height of the bone defect.

Reviewer I: In the collagen samples there seems to be a "hole" with no bone in the centre of the defect. What did you see there by histology?

Authors: These data are illustrated in Fig. 8 with the COL+ BMP figure being the most relevant to this question. This "bubble" region is not an area of inflammation - it is a region bounded by a thin cortex of bone with a marrowlike space with some residual trabeculae. These findings are comparable to prior experiments published with ectopic bone formation models using these implants including $\mathrm{Yu}$ et al. (2013). Note that slower degrading polymer implants show residual polymer at these same time points, such as in Yu et al. (2010).

Reviewer I: An important problem with BMPs appears to be local inflammation and swelling, which probably is responsible for the more serious adverse events. You suggest that a slower release would remedy that. Is there any evidence for a change in "swelling/bone formation" ratio with lower concentrations?

Authors: The effects of BMPs on inflammation are certainly dose dependent, and there is a body of literature 
to support this. One relevant study is by Lee et al. (2012). In this study both rhBMP-2 and rhBMP-7 are examined and shown to increase inflammatory cytokines in a dose dependent manner. Clinically, the complications associated with rhBMP use are associated with a strong initial inflammatory response. Thus we hypothesise that these problems may be minimised by a slower release system that mitigates early inflammation.

Reviewer II: The typical benefit of adding multiple therapies on a single platform is usually the reduction in dose of one of the therapeutics (in this case rhBMP-2 with its known concerns). Why were groups with reduced rhBMP-2 doses not tested when anti-resorptive drugs were being used in conjunction since previous literature has apparently already tested BMP and bisphosphonates together?

Authors: The main rationale for this experimental design was to have appropriate controls. Having a lower rhBMP-2 dose with anti-resorptives would mean that the effects of the different anti-resorptives could not be compared to a relevant control (i.e. the same dose of rhBMP-2 alone). One alternative/additional group that could have further demonstrated this point would have been a higher-dose rhBMP-2 group. However, the finding that a higher dose of rhBMP-2 would generate more bone would have been a fairly obvious outcome, and one that has been previously demonstrated.

Reviewer II: There is extensive peri-cortical callus response along the intact interfacial bone showing a robust regenerative response. Would the authors comment on any difference observed in the callus response between the different groups.

Authors: A greater peri-cortical response was found in the collagen (COL) scaffolds compared to PLGA scaffolds loaded with rhBMP-2. We hypothesise this is due to the superior implant interface osteointegration with COL scaffolds, leading to stimulation of the periosteum at the edge of the defect in those samples. This hypothesis will likely be confirmed in the future using PLGA implant designs that overlap with the original cortex, which should improve interface osteointegration.

Reviewer II: Sutures were threaded to the scaffolds to keep them in place. Despite this, a relatively high misalignment of scaffolds was observed ( $\sim 10 \%)$. Additionally, it is unclear if the collagen scaffolds were also similarly restrained. If they were restrained, what was the variation in the TV of the collagen + BMP sponges, or how inconsistently did they regenerate undesired ossification outside the defect region?

Authors: We also noted the $\sim 10 \%$ misalignment of the TIPS polymer scaffolds, which were sutured in place using a method also used for the collagen scaffolds. Collagen scaffolds created a bone mass that typically spanned the defect gap so misalignment was not apparent, which may reflect a potential advantage of collagen. In future, we would propose modifying our methodology to use additional sutures to more securely anchor the TIPS polymer scaffolds. For clinical translation we would also consider varying the design so as rather than using a solid cylindrical implant to be press fit in the defect, we would use a cylindrical tube that could wrap around and encircle the bone ends of the defect.

Reviewer III: Do you have any supporting data on the kinetics of drug release from your scaffolds?

Authors: We have previously looked at drug elution from these scaffolds in comparison with porous collagen. These data are published in Yu et al. (2013).

Reviewer III: Do you think there is strong evidence in the literature on the most appropriate rate of release for BMPs? Authors: There is not strong evidence in the literature for an optimal rate of release of rhBMP-2. A minimal dose of rhBMP is required for induction of new bone, indicating that a certain degree of burst release is required. However, as previously discussed the inflammation associated with BMPs means that a slower release is an increasingly utilised strategy (Srouji et al., 2011; Wu et al., 2011).

Reviewer III: The PLGA material you used is fast degrading and others have expressed concerns about negative effects from degradation products. Do you think the literature is supportive of the use of this polymer class if it is restricted to use as a highly porous biomaterial within vascularised tissues? My group do not observe any problems with PLGA breakdown when we use highly porous scaffolds and we assume that the dose of acid byproducts is low compared to the tissue volume around the scaffold.

Authors: The presence of acidic breakdown products is an often cited concern. However, in practise this does not seem to translate into major problems for bone repair. In one of the first studies by Rokkanen et al. (1985), it was reported that a PLGA implant healed ankle fractures $5 \mathrm{~d}$ faster than conventional metal implants. However, it is possible that finding methods for reducing the low $\mathrm{pH}$ potentially created by PLGA implants may yield superior outcomes. One method for accomplishing this may be a bulk reduction in the amount of polymer by using a highly porous implant (such as we have done). In addition, others have incorporated other materials into PLGA to counter the acidic degradation products. Liu et al. (2006) investigated and showed this using titania nanoparticles. We propose that ceramic microparticles may be able to achieve a similar outcome, with ceramics being able to neutralise acidic biproducts.

\section{Additional References}

Lee K-B, Taghavi CE, Murray SS, Song K-J, Keorochana G, Wang JC (2012). BMP induced inflammation: a comparison of rhBMP-7 and rhBMP-2. J Orthop Res 30: 1985-1994.

Liu H, Slamovich EB, Webster TJ (2006) Less harmful acidic degradation of poly(lacticco-glycolic acid) bone 
tissue engineering scaffolds through titania nanoparticle addition. Int J Nanomed 1: 541-545.

Rokkanen P, Bostman O, Vainionpää S, Vihtonen K, Törmälä P, Laiho J, Kilpikari J, Tamminmäki M (1985) Biodegradable implants in fracture fixation: early results of treatment of fractures of the ankle. Lancet 325: 1422 1424.

Srouji S, Ben-David D, Lotan R, Livne E, Avrahami R, Zussman E (2011) Slow-release human recombinant bone morphogenetic protein-2 embedded within electrospun scaffolds for regeneration of bone defect: in vitro and in vivo evaluation. Tissue Eng Part A 17: 269-277.

Wu ZX, Liu D, Wan SY, Cui G, Zhang Y, Lei W (2011) Sustained-release rhBMP-2 increased bone mass and bone strength in an ovine model of postmenopausal osteoporosis. J Orthop Sci. 16: 99-104. 